\title{
Health care had a decade of "abundance," CIHI says
}

Published at www.cmaj.ca on Nov. 27

$\mathrm{T}$ he delivery of health care in Canada has changed dramatically over the past 10 years, especially when compared to the "unprecedented period of mid-decade restraint" that concluded at the end of the 1990s, the Canadian Institute for Health Information (CIHI) says in a recent report.

"The past decade in Canadian health care can best be described as one of abundance," Graham Scott, chair of the CIHI board, told an Economic Club of Canada event in Ottawa, Ontario. "But let me qualify that. I don't use that term to imply the system has been overrun by money or that too much has been spent. On the heels of the unprecedented restraint and funding cuts of the 1990s, there was a lot of ground to make up. The last 10 years have seen the biggest sustained spending increases since the dawn of Medicare."

Where has the money gone? Some of it - about $\$ 6$ billion - was dedicated to reducing wait times in five priority areas: joint replacement (hip and knee), cataract surgery, coronary artery bypass grafts, radiation therapy and diagnostic imaging (magnetic resonance imaging and computed tomography), according to CIHI's report Health Care in Canada 2009: A Decade in Review (http://secure.cihi.ca/cihiweb/products /HCIC_2009_Web_e.pdf.).

As a result, the report stated, wait times have declined for hip and knee replacement and for cataract surgery. But the Wait Time Alliance noted in a report, Unfinished Business: Report Card on Wait Times in Canada, last June that some provinces are not progressing well in reducing wait times and that there is a lack of uniform and timely information about wait times.

Money has also been invested in tailored drug therapies, diagnostic technology, training health care professionals and to increase class sizes in medical and nursing schools, says the CIHI report, released Oct. 29. In 2008, Canada

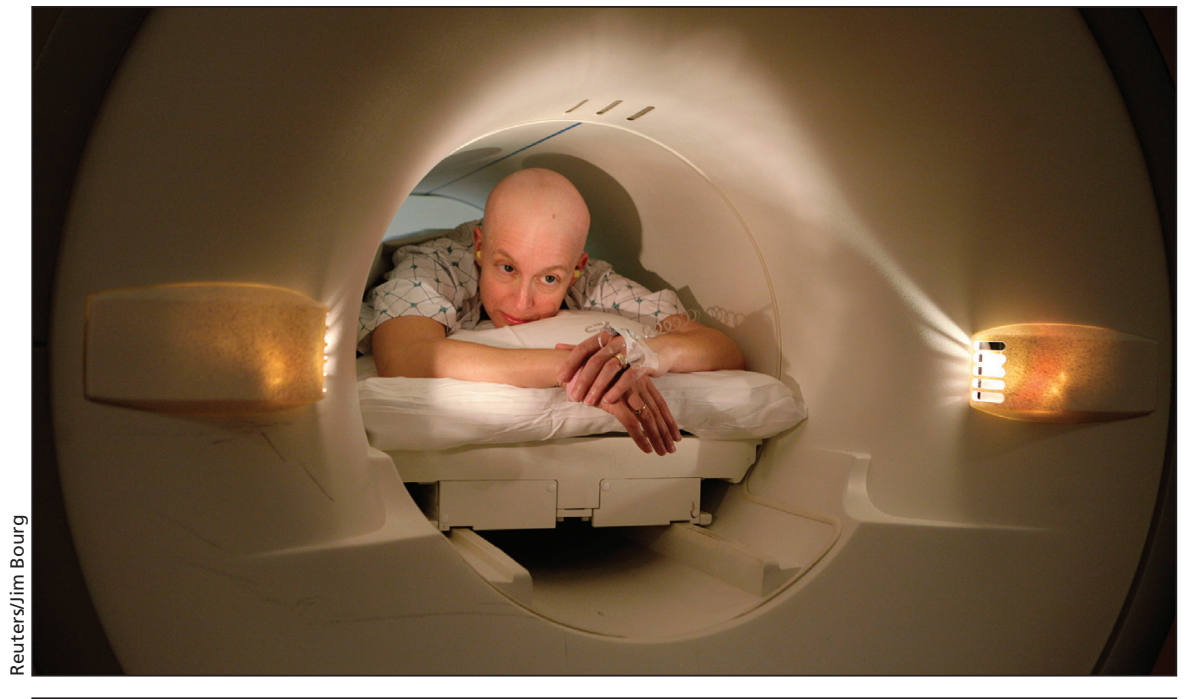

The Canadian health care system has enjoyed a decade of abundance, according to the Canadian Institute for Health Information, with large amounts of money invested in many areas, including diagnostic imaging technologies.

invested $\$ 172$ billion in health care overall, an increase of nearly $60 \%$ from 10 years ago.

Positive results stemming from health care investments include an increase in life expectancy of three years (to 81 years in 2006 from 78 years in 1996) and a substantial decline in heart attacks and deaths following heart attacks, CIHI said.

"Traditionally, heart attacks have been a leading killer of Canadians, but over the past decade, we've made great progress in both reducing the frequency of heart attacks, as well as improving the quality of treatment for patients who have them," said Scott.

"Overall, fewer Canadians are having heart attacks, and fewer are dying from them. So what's driving this? Well, the successful efforts of public health campaigns to reduce smoking rates have certainly played a role. The use of Aspirin, beta-blockers and statins has become more routine, so we're seeing fewer people with severe heart blockages. Thanks to better frontline cardiac care, those who suffer heart attacks are getting their surgery sooner. Almost half of them are on the table within a day of admission to hospital.
Five years ago, only a third were on the table that fast."

Scott noted, however, that there are still areas in the health care system that require further investment - an important one being information technology. Better technology in health care saves time and duplication of care, said Scott, and the widespread use of electronic health records, in particular, has the potential to improve best practices, clinical research, resource planning, outcome monitoring and adverse event tracking.

"I would argue that the future of our health care system will be very much influenced by the electronic health record," said Scott. "The idea is that no matter where you are in the country, if you need care, a health professional can access your entire patient chart with details on medications, past procedures, tests and any conditions or allergies you might have. That avoids duplicating tests, wasting time by sharing your patient history at every new point of care and filling unnecessary prescriptions. This is more efficient and it's safer." - Roger Collier, CMAJ

DOI:10.1503/cmaj.109-3118 